Author version; might slightly differ from published version 
Volunteer work in youth organizations: Predicting distinct aspects of volunteering behavior from self- and other-oriented motives.

Ilse Cornelis and Alain Van Hiel Ghent University

\section{David De Cremer}

Erasmus University, Rotterdam School of Management

Ghent University

WORD COUNT: 6291

Correspondence concerning this article should be sent to Ilse Cornelis, Department of Developmental, Personality and Social Psychology, H. Dunantlaan 2, B-9000 Gent, Belgium. Telephone: + 32926462 69. Fax: +329264 64 99. E-mail: Ilse.Cornelis@UGent.be. 


\begin{abstract}
This study examined the impact of motivational underpinnings of volunteerism on self-reported volunteer behaviors and satisfaction. Data from 153 volunteers in youth organizations supported a two-dimensional structure of self- and other-oriented motives. Selforiented motives were more important in explaining in-role volunteer behavior, while otheroriented concerns were also important in predicting extra-role volunteer behavior and satisfaction. These findings are discussed in the context of a functional approach to volunteerism and linked to recent findings regarding the role of self-and other oriented motives from the organizational literature. Suggestions for recruiting and motivating young volunteers in youth development organizations are presented.
\end{abstract}

Keywords: Motivation, Volunteerism, Pro-social, Cooperation 
Volunteer work in youth organizations: Predicting distinct aspects of volunteering behavior from self- and other-oriented motives.

Many people engage in volunteering, providing important contributions to both the community and the economy (Corporation for National and Community Service, 2007). Volunteering is commonly defined as "any activity in which time is given freely to benefit another person, group, or organization" (Wilson, 2000, p. 215) and formal volunteering refers to pro-social actions undertaken through a volunteering organization (Houle, Sagarin, \& Kaplan, 2005). Whether volunteering reflects altruism or self-interest is an ongoing controversy that parallels the altruism-egoism debate in social psychological research. However, while previous research has examined motives underlying people's volunteering engagement, the impact of these motives on distinct aspects of volunteer performance has not yet been investigated. Using motives identified in the Functional Analysis framework (Clary \& Snyder, 1999) and Motives for Community Involvement (Batson, Ahmad, \& Tsang, 2002) we investigated to what extent self- and other-oriented volunteering motives are important in explaining volunteer performance and satisfaction in youth organizations.

\section{Self-interest or concern for others?}

Why people spend considerable time and effort in order to help others has fascinated social scientists for a long time (for an overview, see Clary et al, 1998; Penner, Dovidio, Piliavin, \& Schroeder, 2005) and the altruism-egoism debate reflects two opposing answers to this question. On the one hand, some scholars believe that helpful behaviors can be truly altruistic, driven by a desire to increase others' well-being (e.g. Batson, 1991). According to this perspective, people volunteer because they want to increase the welfare of others or contribute to the community. Supportive evidence by Clary and Orenstein (1991), for example, demonstrated that crisis centre volunteers were more likely to sustain their efforts 
when motivated by altruistic, rather than self-oriented concerns. On the other hand, it has been proposed that seemingly generous and altruistic acts are driven by selfish concerns, for example when people help needy others because of anticipated praise or to escape possible guilt (e.g. Schaller \& Cialdini, 1988). Particularly for long-term helping such as formal volunteering altruistic motives might not be sufficient. Indeed, AIDS-volunteers who reported other-focused motives such as humanitarianism have been show to remain active for a shorter period than those who cited self-oriented motivations, such as personal development (Omoto \& Snyder, 1995).

In short, even though human nature in general is perceived to be motivated primarily by self -interest (e.g., Kohn, 1990; Wuthnow, 1991), empirical research has suggested that in some contexts, humans are capable of altruism (e.g. Batson, 1991) and it seems that volunteering can be driven by a mixture of both self-focused motives and other interested consideration (Clary \& Snyder, 1999). Hence, it is important to investigate more in detail the multiple motives that lead people to volunteer and to examine how they map onto the distinction between self- and other oriented concerns.

\section{Multiple motives: A functional approach of volunteering and motives for community}

\section{involvement}

Several studies identifying the underlying motives of volunteering (e.g. Clary \& Snyder, 1999; Finkelstein, 2008; Omoto \& Snyder, 1995) have been based on a Functional Analysis perspective. This theory proposes that volunteering fulfills people's individual motives and that the same volunteer work can satisfy different psychological motives (Clary $\&$ Snyder, 1999). Six motives or 'functions' have been identified and operationalized in the Volunteer Functions Inventory (Clary et al. 1998), the majority of them seemingly referring more to self- rather than other-oriented concerns. Indeed, as Snyder and Omoto (2009) also noted in their review of theoretical and empirical work on volunteerism, volunteering driven 
by the desire to learn or exercise skills (Understanding), counter personal problems and negative feelings (Protective), gain career-relevant experience (Career), strengthen one's own social relationships (Social) or stimulate one's own individual growth and development (Enhancement) reflects a focus on personal benefits. Only the Values function, or volunteering driven by a desire to act on important values such as humanitarianism, has a main focus that lies beyond immediate self-benefits, although is still has an expressive function for the self. It thus seems that motives within a functional analysis framework primarily reflect a self-oriented perspective.

However, volunteering is also conceptualized as a sub-domain of community involvement, since it refers to an individual's contribution to address societal problems by participating in community groups and organizations (Stukas \& Dunlap, 2002). From this perspective, it has been - theoretically - argued that people often get involved in a community out of other-oriented concerns (Batson et al., 2002; Omoto \& Snyder, 2002; see also Simon, Sturmer, \& Steffens, 2000, for empirical evidence). Batson and colleagues (2002) have proposed four different motives underlying community involvement. Egoism is clearly selforiented since the ultimate goal is to increase one's own welfare. However, the three remaining motives reflect other-oriented concerns since they refer to ultimate goals of increasing the welfare of others (Altruism), increasing the welfare of a collective (Collectivism) or upholding universal and impartial moral principles (Principlism).

In the present study we jointly examine motives drawn from both the Functional Analysis and community involvement perspective. This approach allows us to investigate how these motives map onto the self/other-oriented dimensions and provides an opportunity to examine the impact of self-and other oriented motives on volunteering outcomes. We propose that motives from the Functional perspective (with the exception of Values) as well 
as Egoism map onto a self-oriented dimension, while the other community involvement motives and Values map represent a focus on other-related concerns (Hypothesis 1).

\section{Distinct types of volunteer behavior}

Previous research has often focused on relatively global outcomes such as sustaining volunteer work (e.g. Finkelstein, Penner, \& Brannick, 2005; Hidalgo \& Moreno, 2009; Omoto \& Snyder, 1995), satisfaction with the volunteering experience (e.g. Clary et al., 1998; Davis, Hall, \& Meyer, 2003), and time spent volunteering (Davis et al, 2003; Finkelstein et al., 2005). However, people with different underlying motives can be expected to prefer different tasks (Houle et al., 2005) and, according to Stukas and Dunlap (2002), different motives can

"... play a very important role in predicting outcomes from community involvement or the quality of the behaviors enacted in the context of involvement..." (p. 416). However, previous research on volunteering tended to neglect different aspects of volunteer performance. Here, we investigated to what extent self- and other-oriented motives that underlie different aspect of volunteering behavior and satisfaction.

In a sense, our work represents a complement to earlier research demonstrating the applicability of the functional perspective, originally developed for unpaid volunteering, to explain paid employees engagement in voluntary (extra-role) pro-social behaviors (e.g. Finkelstein, 2006; Finkelstein \& Penner, 2004, Rioux \& Penner, 2001). However, it is equally possible to apply models originally conceptualized for paid employees to a setting of unpaid volunteers. Here, we examined two types of volunteer performance using a distinction prevalent in organizational research with paid employees (e.g., Riketta, 2002; Tyler \& Blader, 2000). One type of performance, often coined in-role behavior refers to people's contribution of time and effort to activities that are formally expected. Another type of performance, organizational citizenship behavior (OCB) or extra-role behavior, refers to individual discretionary helping not formally required or rewarded by the organization. Both benefit the 
organization but have been differently linked to antecedent and outcome variables (e.g., Podsakoff, Whiting, Podsakoff, \& Blume, 2009; Riketta, 2002). While this distinction is common practice in research with paid employees, Tyler and Blader (2000) proposed that these two forms of behavior capture cooperation in social groups "...varying in their formality and nature. (p.17)", suggesting their relevance for unpaid volunteers as well.

We here distinguished between volunteers' In-role- behavior and Extra-role behavior. In-role volunteer behavior refers to activities prescribed in the role of volunteering in this organization. In-role behaviors have been associated with the likelihood that engaging in them will be rewarding for oneself (Tyler \& Blader, 2000), suggesting they are more strongly associated with self- rather than other-oriented motives (Hypothesis 2). Extra-role behavior on the other hand refers to behaviors not expected or included in the role of volunteering. Because it reflects a willingness to contribute to the group by doing more than expected, it is linked to motives that go beyond self-interested concerns (e.g. Tyler, 1999) and we therefore expected other-oriented motives to also be associated with volunteers' engagement in these behaviors (Hypothesis 3).

We also investigated satisfaction with the volunteering experience, a crucial aspect that also positively influences the time spent volunteering (Finkelstein, 2008) and volunteer longevity (Omoto \& Snyder, 1995). Previous studies on volunteer satisfaction reported considerable correlations with VFI-motives, in particular with VFI-Values which refers to concerns beyond self-benefits (e.g. Finkelstein, 2008; Finkelstein, Penner \& Brannick, 2005; Omoto \& Snyder, 1995). However, while Finkelstein et al. (2005) present regression analyses demonstrating the relative impact of different interrelated motives on time and length of volunteering, it is unclear how these motives jointly influence satisfaction with volunteering experience, i.e. whether one motive would still impact satisfaction over and beyond the influence of the other motives. Here we examined the hypothesis that other-oriented motives 
explain additional variance over and beyond self-related concerns in volunteer satisfaction in youth organizations (Hypothesis 4).

\section{Present study}

The first goal of this study is to demonstrate that motives from a functional analysis approach and motives for community involvement fit within a two dimensional framework of self- and other oriented concerns (Hypothesis 1). The second goal is to investigate the relationships of self- and other-oriented motives with self-reported in-role and extra-role volunteer performance and volunteer satisfaction in youth organizations.

Even though a common and widespread belief holds that self-interest is the primary motivation force behind many human endeavors, self-interest is not necessarily inconsistent with altruistic behavior and indeed volunteering has been shown to be related to motives that refer to self -interest as well as other-related concerns (Clary \& Snyder, 1999). Given this prevalent common notion that pro-social behaviors such as sustained volunteering are often driven by (anticipated) self-benefits (e.g., Omoto \& Snyder, 1995), we particularly wanted to investigate to what extent other-oriented motives can predict additional variation beyond selforiented motives, and to what extent self-and other-oriented motives are differently related to distinct types of volunteer performance and volunteer satisfaction. We test the assumptions that in-role volunteer behavior is predicted by self-oriented motives (Hypothesis 2) while extra-role volunteering and volunteering satisfaction are predicted by both self- and other oriented motives (Hypothesis 3 and Hypothesis 4).

This study contributes to the existing literature for several reasons. First, the joint impact of functional approach motives (mostly self-oriented) and motives for community involvement (mostly other-oriented) is investigated, capturing a more comprehensive range of motives. Secondly, along with satisfaction with volunteering, two forms of volunteer performance are examined, allowing a more fine-grained analysis of the impact of their 
motivational underpinning. Finally, we examined young volunteers engaged in youth development. Previous studies have indicated that different motives might be important to volunteers from different age groups. For example, the career function is often rated as more important to younger than to older volunteers (Clary \& Snyder 1999, see also Eley \& Kirk, 2002; Oesterle, Kirkpatrick-Johnson \& Mortimer, 2004). The sector of youth development has received only very limited attention from researchers (for an exception see Stukas, Daly, \& Clary, 2006)) and it is unclear to what extent motives and processes relevant in very different contexts (for example with Aids/HIV volunteers, Omoto \& Snyder, 1995; Penner \& Finkelstein, 1998; or hospice volunteers, Finkelstein 2008) apply in the context of youth development.

\section{Method}

\section{Participants}

Participants were 153 (77 women and 76 men) youth group 'leader' volunteers, responsible for a group of younger members from three major Flemish youth organizations. All three organizations organize fun and exciting leisure activities for children and adolescents between age 6 -18 while aiming to stimulate values such as justice, respect, peace and understanding. Chiro is the largest youth organization in Flanders with approximately 77000 young members, grouped in nearly 1000 'groups' led by 15000 leader volunteers who are usually between 18 and 26. Scouting and Guiding represents the Flemish division of the international Scout youth movement and has approximately 75000 members, including the volunteer leaders. The KSJ/KSA is a smaller national organization (approximately 35000 members) but very similar in structure, mission and age ranges as both Chiro and Scouts. Typically, youth group leader volunteers plan and coordinate the group's weekly activities and excursions, organize and participate in summer camps, and lead meetings. On average, they had been a volunteer for 3.25 years $(S D=2.69)$ and their mean age was $20.37(S D=$ 
3.52). The large majority of these volunteers were students (86\%). They were contacted through a research assistant who distributed and collected the questionnaires and ensured confidentiality.

\section{Measures}

All items were rated on a 5-point Likert scale ranging from 'not at all important/accurate for you' to 'extremely important/accurate for you', unless otherwise indicated.

Volunteer Functions Inventory (VFI). Respondents completed an adapted version of the Volunteer Functions Inventory (Clary et al., 1998). This scale consists of six subscales: Values (e.g. "I feel it is important to help others"), Understanding (e.g. "Volunteering lets me learn through direct, hands-on experience"), Enhancement (e.g. "Volunteering makes me feel better about myself", Career (e.g. "Volunteering experience will look good on my resume"), Social (e.g. "My friends volunteer") and Protective (e.g. "By volunteering, I feel less lonely"). Pilot testing in a focus group indicated that seven items (three Values, two Career, one Protective and one Understanding) were not applicable to the context of youth volunteering in Flanders and these items were dropped ${ }^{1}$.

Motives for Community Involvement (MCI). Motives for community involvement (Batson et al., 2002) were measured by four self-constructed 5-item scales. The items were sampled from different sources (Farrell, Johnston, \& Twynam,1998; Omoto \& Snyder, 1995; Wang, 2004) measuring Altruism (e.g. "Through my volunteer work I want to help others”), Collectivism (e.g. " I volunteer out of concern for the community”), Principlism (e.g. "I volunteer because I want to do something valuable") and Egoism (e.g. "I hope to achieve something for myself through volunteering that would otherwise be out of reach"). The full scales can be found in Appendix 1. 
Volunteering behaviors. Three items measured In-role behavior (e.g. "I perform the tasks that are expected of me as part of my 'job' as volunteer”) and six items refer to Extra-role behavior (e.g. "I lend a helping hand to others when they have a heavy workload). Five items were taken from Tyler and Blader's (2000) Cooperative Behavior Measure, and 4 additional items for the Extra-role scale were derived from Konovsky \& Organ's (1996) measure of Organizational Citizenship Behavior (OCB). All items were rated on a 5-point Likert scale ranging from 'completely disagree' to 'completely agree'.

Satisfaction. Two items measured overall satisfaction with volunteering: "Overall I am very satisfied with my current position and tasks within the youth organization" and "If a friend would tell me (s)h was interested in volunteering in a youth organization, I would strongly recommend it"

\section{Results}

Descriptive statistics, Cronbach Alpha's and correlations can be found in Table 1 . While several subscales have low internal consistencies (VFI-Career, VFI-Values, MCI Altruism, and Satisfaction), some authors have reported values of .60 as acceptable (Robinson, Shaver, \& Wrightsman, 1991). Furthermore, some subscales might represent formative indicators of a composite latent variable rather than mutually interchangeable indicators reflecting the underlying latent construct (e.g. MacCallum \& Browne, 1993), which could also account for lower alphas.

The VFI motives Understanding, Values and Social were rated as somewhat more important, while the VFI- Protective function had the lowest average score. Altruism was the strongest endorsed MCI subscale.

\section{Insert Table 1 about here}

Self- and other-oriented motives: two dimensions? 
First, separate Confirmatory Factor Analyses models were tested for VFI and MCI, with each item loading on the designated latent subscale variable. These models demonstrated adequate to good fit (see Table 2). Next, the factor structure of volunteer motives was examined. Exploratory Factor Analysis (EFA) followed by Oblimin rotation on the subscale scores indicated a two-factor solution (eigenvalues after rotation 3.27 and 2.59) explaining a total of $44 \%$ of the variance. All VFI subscales as well as the MCI subscale 'MCI- Egoism' loaded higher than .41 on the first factor, whereas the other MCI subscales loaded on the second factor (loadings >.57). 'VFI -Values' also had a cross-loading of .40 on the second factor. Hence, the EFA indicated a two-factor solution.

We further tested this two-factor solution in a Confirmatory Factor Analysis (CFA). Compared to EFA, CFA allows statistical tests for goodness of fit of the proposed factor structure and constraining or relaxing various parameters allows to test alternative configurations, On theoretical grounds, we expected all VFI subscales except 'VFI -Values', as well as the MCI subscale 'MCI- Egoism' to load on a higher order 'Self-oriented' latent factor, while the other MCI subscales and 'VFI-Values' load on a higher order 'Otheroriented' latent factor. This model (Model A, Table 2) demonstrated good fit, but modification indices specified that the 'VFI -Values' subscale should (also) load on the 'Selforiented' latent factor (a result similar to the one found in EFA). Allowing VFI-Values to load on both higher order latent factors indeed resulted in significantly improved model fit; $\left.\Delta \chi^{2}(1)=5.71, p<.05\right)$. Given that this subscale had significant and substantial cross-loadings and because of its low internal consistency, we re-estimated a VFI-model without 'Values' and examined a model with Self- and Other oriented higher order factors without VFI-Values (Model B). This model yielded a good fit to the data and also a significantly better fit than a model where all subscales load on a single higher order factor (Model B') $\left(\Delta \chi^{2}(1)=13.38, p\right.$ <. 001). Hence, in line with our first hypothesis, motives represented in the VFI and the MCI 
framework can be adequately mapped onto a higher order two-dimensional perspective of self- and other-oriented motives (see Figure 1). In the remainder, we used subscale scores as predictors, grouped together in blocks of self- and other oriented motives.

\section{Insert Table 2 about here}

\section{Insert Figure 1 about here}

Impact of self-and other oriented motives on volunteer performance and satisfaction ${ }^{2}$

In-role. Self-oriented motives explained $24 \%$ of the total variance of In-role behavior, $F(6,144)=7.76, p<.01$. Adding other-oriented motives in a second step did not significantly increase the amount of variance explained, $\Delta R^{2}=.02, \Delta F(3,141)=1.26, n s$. Reversing the order of entering other- and self-oriented motives, self-oriented motives explained a significant additional $17 \%$ of the variance, $\Delta F(6,141)=5.39, p<.01$, beyond the initial variance captured by other-oriented motives, $R^{2}=.10, F(3,147)=5.16, p<.01$. These findings are in line with Hypothesis 2 that in-role volunteer behaviors are predicted mainly by self-oriented volunteering motives. VFI-Understanding was positively and VFI-Protective negatively associated with in-role volunteer behavior (see Table 3).

\section{Insert Table 3 about here}

Extra-role. Self-oriented motives alone explained more than a quarter of the variance in Extra-Role behavior, $R^{2}=.27, F(6,145)=8.73, p<.01$. Adding other-oriented motives in a second step significantly increased the explained variance, $\Delta R^{2}=.10, \Delta F(3,142)=7.30, p$ $<.01$. Reversing the order, other-oriented motives initially predicted $24 \%$ of the variance, $F(3$, $148)=15.29, p<.01$, with Self-focused motives contributing a significant but relatively smaller amount of $13 \%, \Delta F(6,141)=4.70, p<.01$. These results confirm our third hypothesis that extra-role behaviors are predicted by both self- and other oriented volunteering motives. Particularly VFI-Understanding, MCI- Altruism and MCI- Collectivism 
were positively associated with higher levels of discretionary volunteer behavior, while MCIPrinciplism was negatively associated.

Satisfaction. Self-oriented motives explained a significant proportion of the variance in satisfaction, $R^{2}=.23, F(6,143)=7.21, p<.01$, and adding other-oriented motives significantly increased this explained variance, $\Delta R^{2}=.06, \Delta F(3,140)=3.83, p<.05$, providing evidence for our Hypothesis 4. In the reverse order, self-oriented motives explained an additional $16 \%$ of the variance, $\Delta F(6,140)=5.36, p<.01$, above and beyond the initial variance accounted for by other-oriented motives, $R^{2}=.13, F(3,146)=7.11, p<.01$, suggesting that both self-and other oriented motives independently contribute to satisfaction with the volunteering experience. Satisfaction with volunteering was positively associated with VFI- Understanding, VFI-Social, MCI-Egoism and MCI-Altruism.

\section{Discussion}

This study had two major aims. The first goal was to investigate whether functional analysis and community involvement motives fit within a two dimensional framework of selfand other oriented motives. The second goal was to investigate the impact of self- and otheroriented motives on distinct types of self-reported volunteer performance and volunteer satisfaction.

With respect to the first goal, our findings demonstrated that self- and other-focused volunteer motives do not reflect opposite end points on a continuum, but instead represent two distinct dimensions. The considerable positive correlation between the self- and other-oriented dimension further challenges the view that egoistic and altruistic tendencies necessarily oppose one another, attesting to the fact that people's motivations for volunteering are often complex and driven by a mixture of self-and other related concerns (Clary \& Snyder, 1999). These findings corroborate De Dreu and Nauta (2009) who hypothesized that positive goal interdependence, which is likely in non-competitive contexts like a volunteering situation, 
yields a positive association between self- and other oriented concerns. The usefulness of organizing specific volunteer motives in broader categories has also been demonstrated earlier by Finkelstein (2009) who proposed a dichotomy between extrinsically and intrinsically driven motives. Building on the work of De Dreu and Nauta (2009), we are convinced that organizing specific volunteer motives in broader dimensions of self and other orientation represents a useful tool in the context of volunteering research, particularly when the focus is on the combined impact of motivation and situational roles and social contexts (Penner et al, 2005).

With respect to the second goal, the results not only demonstrated that volunteer outcomes were significantly predicted by self-oriented motives, but also that other-focused motives significantly contributed over and beyond self-oriented motives to explain volunteers' engagement in extra-role volunteer behavior and volunteer satisfaction. Corroborating previous research, these findings thus illustrated the importance of self-oriented motives as driving forces underlying volunteering behavior and satisfaction. However, the present findings also attest to the utility of taking into account other-oriented motives. Interestingly, our result that both self- and other-oriented motives incrementally influence volunteer extra-role behavior and satisfaction nicely aligns with earlier work on multiple volunteer motives. Stukas, Worth, Clary and Snyder (2009) demonstrated that the number of matches between motives and the extent to which the volunteering environment allows these motives to be met is particularly predictive of volunteer outcome, with more matches (more motives being met) yielding higher volunteer satisfaction.

While the VFI questionnaire, which has gained general acceptance among volunteerism researchers as a valid framework of volunteering motivations, presumably contains both self- and other oriented motives, these other-oriented motives are less prominent and have received relatively little attention. Finkelstein (2009) distinguished between 
'internal' (Values, Protective, Understanding, Social, and Enhancement) and 'external' (Career) VFI motives but this distinction reflected whether fulfillment in volunteering was to be found in the volunteering activity itself or outside the volunteer behavior, rather than whether volunteering is undertaken with a focus on the self or others. The present study clarifies that altruism (and collectivism) are important motivations underlying particular manifestations of volunteering behavior. Future studies might thus benefit taking paying attention to the role of these other-oriented motives.

The importance of other-oriented motives in explaining extra-role behavior was predicted from organizational research that has abundantly demonstrated that these behaviors are driven not merely by people's self-interested concerns, but also by people's attitudes towards the group, such as legitimacy perceptions of group leaders and feelings of responsibility towards the group, suggesting underlying motivations that go beyond selfinterest (e.g. Tyler \& Blader, 2000). Other-oriented motives also explained additional variance in volunteer satisfaction, corroborating previous studies showing particularly strong associations with VFI-Values, a facet scale referring to concerns beyond self-benefits (e.g. Finkelstein, 2008; Finkelstein et al., 2005; Omoto \& Snyder, 1995). Because specific VFI and MCI motives were strongly correlated, we also pitted the effects of each specific motive against the effects explained by the other motives. Three noteworthy findings emerged here. First, VFI-Understanding was positively related to volunteer performance (In-Role and ExtraRole) and satisfaction, suggesting it drives youth volunteers to expend more energy in both formally expected and un-mandated activities, resulting in increased satisfaction with the volunteering experience. Second, MCI-Altruism was positively linked to Extra-role behavior and satisfaction, corroborating earlier studies showing that broad altruistic concerns positively influences OCB in paid employees (Ilies, Fulmer, Spitzmuller, \& Johnson, 2009). Finally, we also found significant negative associations between specific motives and volunteer 
performance. Volunteering to escape negative feelings (VFI-Protective) had a counterproductive unique effect on in-role performance. While this might be due by underlying Negative Affectivity, which is associated with decreased performance (Kaplan, Bradley, Luchman, \& Haynes, 2009), it is unclear why this effect only occurs for in-role behavior. Furthermore, it seems that, when we control for altruistic and collective concerns, people who volunteer out of principled concerns (MCI-Principlism) are less likely to engage in extra-role behaviors.

\section{Limitations and strengths}

We relied on cross-sectional self-report survey data which need to be considered critically in terms of common method bias and generalizability. While common measurement may yield artificially inflated correlations, it fails to explain differential patterns of results. Additionally, we here measured volunteer motivations in itself and did not included a measure of good these motives are met ('match') in a particular volunteering situation, which may also have affected volunteer outcomes. Future studies employing multiple sources and including indicators of the match between motives and environment in a longitudinal design could provide a more complete picture and allow to causally predict different types of volunteering performance from self- and other-oriented motives underlying volunteerism.

A possible limitation can be found in the fact that we use both self-developed measures and pre-existing scales demonstrating relatively low reliabilities here. However, we tested the theoretical structure with each item loading on the designated latent subscale variable, and Confirmatory Factor Analysis indicated adequate to good fit with items demonstrating good to excellent loadings on the designated latent factors. This suggests that even while the Cronbach alpha's for two and three-item scales might fail to reach the conventional levels of .70, the items indeed are valid indicators of the proposed constructs. Future research should look into further validating the measures developed here. 
It should further be noted that while we expected that VFI- Values would map onto a broader dimension of other-oriented motives this subscale - unexpectedly- loaded higher on a self-oriented dimension. This could be due to the restricted item content, since our scale was reduced to two items after pilot tests in a focus group showing that the other items were inapplicable to the context of youth development. However, one of the two remaining items that constitute the Values subscale ("I can do something for a cause that is important to $m e$ ") seems to be more strongly self-focused than the other original four Values items.

We studied young volunteers, who are mostly students, working with children in youth organizations. Although student volunteers are often studied, volunteers in youth organizations are a relatively understudied group. This lack of attention is regrettable, because firstly, patterns of volunteer motives might be different in youth development compared to other samples (Stukas et al., 2006). Consistent with other researchers in this sector (e.g. Clary, Snyder, \& Stukas, 1996), our respondents rated Values and Understanding as most important. However, contrary to these previous studies, our respondents also ascribed relatively high importance to the Social function. Secondly, while people in the young age bracket volunteer less than older people (Corporation for National and Community Service, 2007), adults are more likely to volunteer later in life when they have volunteered as adolescents and young adults (Independent sector, 2008). However, Kulik (2010) demonstrated that young female volunteers experience a greater sense of sacrifice, more burnout and less overall volunteering satisfaction than older volunteers, suggesting it is important to pay attention to this particular age group in order to ensure their continued engagement in and satisfaction with volunteering later on in life.

Hence, practical recommendations derived from this research focus on using these insights into creating more positive volunteering experiences for younger volunteers. At the level of active young volunteers, knowledge regarding important motivations behind 
volunteering and the link tot behavioral outcomes should be translated into programs that apply these insights to this particular volunteering setting. Youth development volunteering organizations tend to focus their training efforts on the more practical aspects of day-to-day volunteering and the interpretation of leadership in youth development. However, based on our study, guidance and training focusing on how these young volunteers may adapt their work within groups to fit with personally dominant volunteering motives may ensure increased satisfaction. Furthermore, guiding volunteers to interpret the content of the volunteering experience so it satisfies both other-focused motives as well as more-selforiented motivations will not only bolster their enthusiasm for engaging in 'proscribed' volunteering role behavior but also make them more willing to go the extra mile.

Given that many youth development organizations struggle to attract sufficient volunteers among young people (Bosschaerts, 2009) during a life stage where they have many attractive, time-consuming alternatives to volunteering (such as paid weekend jobs), it is also important to effectively attract potential volunteers. Hence, recruitment efforts aimed at this particular group may want to emphasize the benefits of volunteering in terms of acting on important values, learning and exercising skills and the social rewards available to those who volunteer. Since these benefits refer to the most important motives underlying volunteering, they offer an attractive message that may appeal to many potential candidate-volunteers. However, it is up to the organizations to provide the necessary conditions to allow those volunteers to experience these rewards firsthand in order to maximize young volunteers' satisfaction and retention..

\section{Conclusion}

The present study demonstrated how a more fine- grained analyses of volunteer performance can be the key to untangling previous contradictory findings by revealing how self- and other-oriented volunteering motives differentially relate to various types of 
outcomes. Ultimately, this could allow volunteer organizations to better match individuals' personal motives for volunteering to specific tasks and positions within the volunteering organization, resulting in higher volunteer satisfaction and continuation, as well as optimal volunteer performance. 


\section{References}

Batson, C. D. (1991). The altruism question: Towards a social-psychological answer. Hillsdale, NJ: Erlbaum.

Batson, C. D., Ahmad, N., \& Tsang, J. A. (2002). Four motives for community involvement. Journal of Social Issues, 58, 429-445.

Clary, E. G., \& Orenstein, L. (1991). The amount and effectiveness of help: The relationship of motives and abilities to helping behavior, Personality and Social Psychology Bulletin, $17,58-64$.

Clary, E. G., \& Snyder, M. (1999), The motivations to volunteer: Theoretical and practical considerations. Current Directions in Psychological Science, 8, 156-159.

Clary, E. G., Snyder, M., Ridge, R. D., Copeland, J., Stukas, A. A., Haugen, J., \& Miene, P. (1998). Understanding and assessing the motivations of volunteers: A functional approach. Journal of Personality and Social Psychology, 74, 1516-1530.

Clary, E. G., \& Snyder, M. \& Stukas, A. A. (1996). Volunteers' motivations: Findings from a national survey. Nonprofit and Voluntary Sector Quarterly, 25, 485-505.

Corporation for National and Community Service (2007). Volunteering in America: 2007 State Trends and Rankings in Civic Life, Washington, DC. Retrieved June 2009 from http://www.nationalservice.gov/pdf/VIA/VIA_fullreport.pdf.

Davis, M. H., Hall, J. A., \& Meyer, M. (2003). The first year: Influences on the satisfaction, involvement, and persistence of new community volunteers. Personality and Social Psychology Bulletin, 29, 248-260.

De Dreu, C. K. W. \& Nauta, A. (2009). Self-interest and other-orientation in organizational behavior: Implications for job performance, prosocial behavior, and personal initiative. Journal of Applied Psychology, 94, 913-926. 
Eley, D., \& Kirk, D. (2002). Developing citizenship through sport: The impact of a sportbased volunteer programme on young sport leaders. Sport Education and Society, 7, 151-166.

Farrell, J. M., Johnston, M. E., \& Twynam, G. D. (1998). Volunteer motivation, satisfaction, and management at an elite sporting competition. Journal of Sport Management, 12, 288-300.

Finkelstein, M. A. (2008). Volunteer satisfaction and volunteer action: A functional approach. Social Behavior and Personality, 36, 9-18.

Finkelstein, M. A. (2009). Intrinsic vs. extrinsic motivational orientations and the volunteer process. Personality and Individual Differences, 46, 653-658.

Finkelstein, M. A., \& Penner, L. A. (2004). Predicting organizational citizenship behavior: Integrating the functional and role identity approaches. Social Behavior and Personality, 32, 383-398.

Bossschaerts, I. (2009, July $9^{\text {th)}}$ : Jeugdbewegingen vinden geen leiders meer [Youth organizations no longer find leaders]. Het Nieuwsblad. Retrieved from http://www.nieuwsblad.be.Hidalgo, M. C., \& Moreno, P. (2009). Organizational socialization of volunteers: the effect on their intention to remain. Journal of Community Psychology, 37, 594-601.

Houle, B. J., Sagarin, B. J., \& Kaplan, M. F. (2005). A functional approach to volunteerism: Do volunteer motives predict task preference? Basic and Applied Social Psychology, 27, $337-344$.

Ilies, R., Fulmer, I. S., Spitzmuller, M., \& Johnson, M. D. (2009). Personality and citizenship behavior: The mediating role of job satisfaction. Journal of Applied Psychology, 94, 945-959. 
Independent Sector (2008). Engaging Youth in Lifelong Service, retrieved June 2009 from http://www.independentsector.org/programs/research/ engagingyouth.html.

Kaplan, S. A., Bradley, J., Luchman, J. N., \& Haynes, D. (2009). On the role of positive and negative affectivity in job performance: A meta-analytic investigation. Journal of Applied Psychology, 94, 162-176.

Konovsky, M. A., \& Organ, D. W. (1996). Dispositional and contextual determinants of organizational citizenship behavior. Journal of Organizational Behavior, 17, 253-266.

Kohn, A. (1990). The brighter side of human nature. New York: Basic Books.

Kulik, L. (2006). Burnout among volunteers in the social services: The impact of gender and employment status. Journal of Community Psychology, 34, 541-561.

Kulik, L. (2010). Women's experiences with volunteering: A comparative analysis by stages of the life cycle. Journal of Applied Social Psychology, 40, 360-388.

Maccallum, R. C., \& Browne, M. W. (1993). The use of causal indicators in covariance structure models - Some practical issues. Psychological Bulletin, 114, 533-541.

Oesterle, S., Kirkpatrick-Johnson, M. \& Mortimer, J.T. (2004). Volunteerism during the transition to adulthood: A life course perspective. Social Forces, 82, 1123-49.

Omoto, A. M., \& Snyder, M. (1995). Sustained helping without obligation - Motivation, longevity of service, and perceived attitude-change among aids volunteers. Journal of Personality and Social Psychology, 68, 671-686.

Omoto, A. M., \& Snyder, M. (2002). Considerations of community: The context and process of volunteerism. American Behavioral Scientist, 45, 846-867.

Penner, L. A., Dovidio, J. F., Piliavin, J. A., \& Schroeder, D. A. (2005). Prosocial behavior: Multilevel perspectives. Annual Review of Psychology, 56, 365-392.

Penner, L.A., \& Finkelstein, M.A. (1998). Dispositional and structural determinants of volunteerism. Journal of Personality and Social Psychology, 74, 525-537. 
Podsakoff , N. P., Whiting, S. W., Podsakoff, P. M., \& Blume, B. D. (2009). Individual- and organizational-level consequences of organizational citizenship behaviors: a metaanalysis. Journal of Applied Psychology, 94, 122-141.

Riketta, M. (2002). Attitudinal organizational commitment and job performance: a metaanalysis. Journal of Organizational Behavior, 23, 257-266.

Rioux, S. M., \& Penner, L. A. (2001). The causes of organizational citizenship behavior: A motivational analysis. Journal of Applied Psychology, 86, 1306-1314.

Robinson, J. P., Shaver, P. R., \& Wrightsman, L. S. (1991). Measures of personality and social psychological attitudes. San Diego: CA: Academic Press.

Schaller, M., \& Cialdini, R. B. (1988). The economics of empathic helping: Support for a mood management motive. Journal of Experimental Social Psychology, 24, 163-181.

Simon, B., Sturmer, S., \& Steffens, K. (2000). Helping individuals or group members? The role of individual and collective identification in AIDS volunteerism. Personality and Social Psychology Bulletin, 26, 497-506.

Snyder, M., \& Omoto, A. M. (2008). Volunteerism: Social issues perspectives and social policy implications. Social Issues and Policy Review, 2, 1-36.

Stukas, A. A., Daly, M., \& Clary, E. G. (2006). Lessons from research on volunteering for mobilizing adults to volunteer for positive youth development. In E. G. Clary \& J. E. Rhodes (Eds.), Mobilizing adults for positive youth development: Strategies for closing the gap between beliefs and behaviors (pp. 65-82). New York, NY: Springer.Stukas, A. A., Dunlap, M. R. (2002). Community involvement: Theoretical approaches and educational initiatives. Journal of Social Issues, 58, 411-427.

Stukas, A. A., Worth, K.A., Clary, E.G., \& Snyder, M. (2009). The matching of motivations to affordances in the volunteer environment. Nonprofit and Voluntary Sector Quarterly, 38, $5-28$. 
Tyler, T. R.(1999). Why people cooperate with organizations: An identity-based perspective. Research in Organizational Behavior, 21, 201-246

Tyler, T. R., \& Blader, S. (2000). Cooperation in groups: Procedural justice, social identity, and behavioral engagement. Philadelphia: Taylor \& Francis.

Wang, P. Z. (2004). Assessing motivations for sports volunteerism. Advances in Consumer Research, 31, 420-425.

Wilson, J. (2000). Volunteering. Annual Review of Sociology, 26, . 215-240.

Wuthnow, R. (1991). Acts of compassion. Princeton, NJ: Princeton University Press. 


\section{Footnotes}

1. Although all three youth organizations invest efforts in attracting members from all parts of society and emphasize diversity, at the moment the large majority of children in the youth groups overseen by the volunteers are from a white middleclass background. This may explain why items such as "I am concerned about those less fortunate than myself" and "Doing volunteer work relieves me of some of the guilt over being more fortunate than others" were deemed less relevant in this context. Furthermore, there are few 'career' options in the context of these organizations, which might explain the omission of two career items.

2. Demographic characteristics such as gender might influence volunteering motives and the experience of volunteering (e.g. Kulik, 2006). All regression analyses were initially run while controlling for volunteers' gender and tenure as a volunteer, however there were no effects of these variables and excluding them from the analyses did not change our findings, therefore we only report the more concise results without control variables. 
Table 1

Means, Standard Deviations, Reliabilities, and Intercorrelations for Volunteer Functions,

Motives for Community Involvement and Volunteer Behavior.

\begin{tabular}{|c|c|c|c|c|c|c|c|c|c|c|c|c|c|}
\hline & 1 & 2 & 3 & 4 & 5 & 6 & 7 & 8 & 9 & 10 & 11 & 12 & 13 \\
\hline 1. VFI - Social & $(.78)$ & & & & & & & & & & & & \\
\hline 2. VFI - Protective & $.36^{\star *}$ & $(.68)$ & & & & & & & & & & & \\
\hline 3. VFI - Career & $.47^{\star *}$ & $.31^{* \star}$ & $(.56)$ & & & & & & & & & & \\
\hline 4. VFI - Enhancement & $.45^{\star *}$ & $.57^{* *}$ & $.54^{* *}$ & $(.71)$ & & & & & & & & & \\
\hline 5. VFI - Understanding & $.38^{* *}$ & $.17^{*}$ & $.31^{* *}$ & $.41^{* *}$ & $(.66)$ & & & & & & & & \\
\hline 6. VFI - Values & $.34^{* *}$ & $.34^{* *}$ & $.35^{\star *}$ & $.43^{* *}$ & $.52^{\star \star}$ & $(.54)$ & & & & & & & \\
\hline 7. $\mathrm{MCl}$-Egoism & $.32^{\star *}$ & $.31^{* *}$ & $.50^{* *}$ & $.50^{* *}$ & $.48^{* *}$ & $.57^{\star \star}$ & $(.70)$ & & & & & & \\
\hline 8. MCl - Altruism & $.21^{*}$ & $.20^{*}$ & $.24^{* *}$ & $.33^{* *}$ & $.39^{* *}$ & $.46^{* *}$ & $.47^{* *}$ & $(.61)$ & & & & & \\
\hline 9. $\mathrm{MCl}$ - Collectivism & $.19^{*}$ & .14 & $.20^{*}$ & $.21^{*}$ & .16 & $.29^{* *}$ & $.14^{* *}$ & $.42^{* *}$ & $(.83)$ & & & & \\
\hline 10. $\mathrm{MCl}$ - Principlism & $.22^{\star *}$ & $.18^{*}$ & $.26^{* *}$ & $.20^{*}$ & $.26^{* *}$ & $.42^{\star \star}$ & $.49^{* *}$ & $.40^{* *}$ & $.48^{* *}$ & (.73) & & & \\
\hline 11. In-role & $.28^{* *}$ & -.04 & $.17^{*}$ & $.28^{* *}$ & $.40^{* *}$ & $.31^{* *}$ & $.28^{* *}$ & $.34^{* *}$ & $.18^{*}$ & $.19^{*}$ & $(.78)$ & & \\
\hline 12. Extra-role & $.25^{\star *}$ & $.26^{* *}$ & $.20^{*}$ & $.37^{* *}$ & $.42^{* *}$ & $.39^{* *}$ & $.37^{* *}$ & $.45^{* *}$ & $.32^{* *}$ & .15 & $.41^{*}$ & $(.72)$ & \\
\hline 13. Satisfaction & $.36^{* *}$ & .05 & .11 & .15 & $.39^{* *}$ & $.27^{* *}$ & $.27^{* *}$ & $.38^{* *}$ & .14 & .11 & $.47^{* *}$ & $.40^{* *}$ & (.65) \\
\hline Mean & 3.92 & 3.11 & 3.72 & 3.57 & 4.10 & 3.94 & 3.75 & 4.17 & 3.24 & 3.29 & 4.32 & 3.78 & 4.41 \\
\hline SD & .69 & .78 & .75 & .65 & .55 & .63 & .62 & .45 & .79 & .69 & .61 & .59 & .61 \\
\hline
\end{tabular}

Note VFI = Volunteer Functions Inventory; MCI = Motives for Community Involvement,

$*=p<.05, * *=p<.01$ 
Table 2: Goodness-of-fit indices for Confirmatory Factor Analyses

\section{SBS $\chi^{2} ;$ df $\quad$ RMSEA $\quad$ SRMR $\quad$ CFI}

$\underline{\text { Separate scales }}$

$V F I$

$\begin{array}{cccccc}\text { Including Values } & 333.84 & 215 & .060 & .076 & .95 \\ \text { Excluding Values } & 295.23 & 179 & .065 & .078 & .94 \\ & 267.63 & 164 & .065 & .079 & .94\end{array}$

$\underline{\text { Two- vs. one dimensions }}$

Model A

$\begin{array}{lllll}1304.37 & 849 & .059 & .087 & .92\end{array}$

Model B

$\begin{array}{lllll}1183.61 & 769 & .059 & .086 & .92\end{array}$

Model B'

$\begin{array}{lllll}1196.99 & 770 \quad .060 & .092 \quad .92\end{array}$

Note $:$ VFI = Volunteer Functions Inventory; $\mathrm{MCI}=$ Motives for Community Involvement,

SBS $\chi^{2}=$ Satorra-Bentler Chi-Squared 
Table 3: Standardized Regression Coefficients

\begin{tabular}{llll}
\hline & In-role & Extra-role & Satisfaction \\
\hline \multicolumn{2}{c}{ Self-oriented motives } & & \\
VFI - Social & .14 & .04 & $.25^{* *}$ \\
VFI - Protective & $-.24^{* *}$ & .08 & -.03 \\
VFI - Career & -.18 & -.08 & -.15 \\
VFI - Enhancement & .20 & .08 & -.16 \\
VFI - Understanding & $.29 * *$ & $.25^{* *}$ & $.28^{* *}$ \\
MCI -Egoism & .08 & .16 & $.21^{*}$ \\
Other-oriented motives & .17 & $.28^{* *}$ & $.26^{* *}$ \\
MCI - Altruism & -.00 & $.17^{*}$ & .00 \\
MCI - Collectivism & -.03 & $-.21^{*}$ & -.17 \\
MCI - Principlism & & & \\
\hline
\end{tabular}

Note: $*=p<.05, * *=p<.01$ 


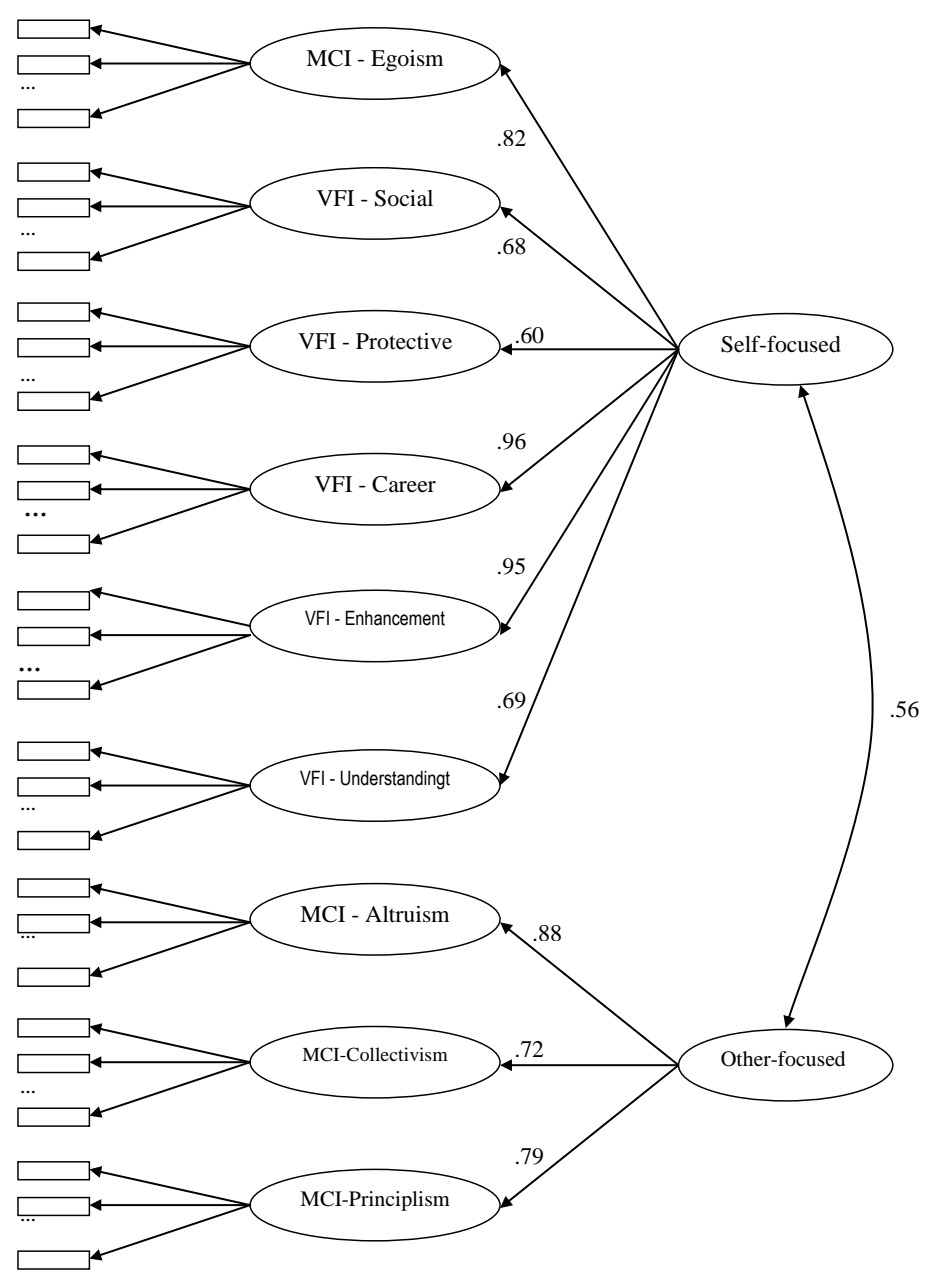

Figure 1. Structural representation of VFI and MCI with two underlying latent dimensions. 
Appendix

Items used to measure the Motives for Community Involvement (MCI)

\author{
Altruism \\ I want to share my knowledge and skills with others \\ I want to help to make the youth organization successful in helping others \\ I want to help together with others as a group \\ Through my volunteer work I want to help others \\ I volunteer because I enjoy helping other people \\ Collectivism
}

I feel that my volunteering benefits the youth organization and community as a whole

Volunteering to me represents a service to the community

I want to do something positive for the community by volunteering

I volunteer out of concern for the community

My engagement as a volunteer makes me feel part of the community

Principilism

I feel that all people should spend some of their time volunteering

I volunteer because I want to do something valuable

I feel it is my moral duty to engage in volunteering

I volunteer out of a human obligation to help and serve others

I think people should volunteer for causes that are important to them

\title{
Egoism
}

I want to get to know people who are interested in the same things as I am

Volunteering makes me feel good about myself

Volunteering makes a positive impression on people around me

I hope to achieve something for myself through volunteering that would otherwise be out of reach

My volunteer work gives me extra perspectives on the future 